\title{
Development of damage curves for buildings near La Rochelle during storm Xynthia based on insurance claims and hydrodynamic simulations
}

\author{
Manuel Andres Diaz Loaiza ${ }^{1,7}$, Jeremy D. Bricker ${ }^{1,6}$, Remi Meynadier ${ }^{2}$, Trang Minh Duong ${ }^{3,4,5}$, \\ Rosh Ranasinghe ${ }^{3,4,5}$, and Sebastiaan N. Jonkman ${ }^{1}$ \\ ${ }^{1}$ Department of Hydraulic Engineering, Delft University of Technology, Delft, the Netherlands \\ ${ }^{2}$ Group Risk Management, AXA GIE, Paris, France \\ ${ }^{3}$ Department of Coastal and Urban Risk and Resilience, IHE Delft Institute for Water Education, \\ P.O. Box 3015, 2601 DA Delft, the Netherlands \\ ${ }^{4}$ Department of Water Engineering and Management, University of Twente, P.O. Box 217, \\ 7500 AE Enschede, the Netherlands \\ ${ }^{5}$ Harbour, Coastal and Offshore Engineering, Deltares, P.O. Box 177, 2600 MH Delft, the Netherlands \\ ${ }^{6}$ Department of Civil and Environmental Engineering, University of Michigan, Ann Arbor, MI, USA \\ ${ }^{7}$ JBA Consulting, Dublin, Ireland
}

Correspondence: Jeremy D. Bricker (j.d.bricker@tudelft.nl)

Received: 4 June 2021 - Discussion started: 18 June 2021

Revised: 15 December 2021 - Accepted: 15 December 2021 - Published: 8 February 2022

\begin{abstract}
The Delft3D hydrodynamic and wave model is used to hindcast the storm surge and waves that impacted La Rochelle, France, and the surrounding area (Aytré, Châtelaillon-Plage, Yves, Fouras, and Île de Ré) during storm Xynthia. These models are validated against tide and wave measurements. The models then estimate the footprint of flow depth, speed, unit discharge, flow momentum flux, significant wave height, wave energy flux, total water depth (flow depth plus wave height), and total (flow plus wave) force at the locations of damaged buildings for which insurance claims data are available. Correlation of the hydrodynamic and wave results with the claims data generates building damage functions. These damage functions are shown to be sensitive to the topography data used in the simulation, as well as the hydrodynamic or wave forcing parameter chosen for the correlation. The most robust damage functions result from highly accurate topographic data and are correlated with water depth or total (flow plus wave) force.
\end{abstract}

\section{Introduction}

In February 2010 the Xynthia extratropical storm caused damage and casualties along the Atlantic coast of Spain and France (Slomp et al., 2010; Chauveau et al., 2011). The strong winds and low atmospheric pressure together with the landfall of the storm at high spring tide generated unprecedented water levels at La Rochelle and surroundings (Bertin et al., 2014). The present paper develops damage curves for buildings in the area where the storm surge and waves from the Xynthia storm caused the most damage. We draw on methods used to quantify damage due to hurricanes and tsunamis in the USA and Japan (Suppasri, 2013; Hatzikyriakou et al., 2018; Tomiczek et al., 2017) but for the first time apply these to modern masonry structures in Europe affected by storm surge and waves from an extratropical cyclone. Therefore, the main objective of the present study is to develop damage functions from insurance claims data supported by hydrodynamic modelling. A total of 423 reported claims in the area of study were used (Fig. 1). The damage ratio (DR) is defined as the ratio of damages claimed by each property to the total insured value of that property. More than $9 \%$ of the structures had a damage ratio (DR) higher 


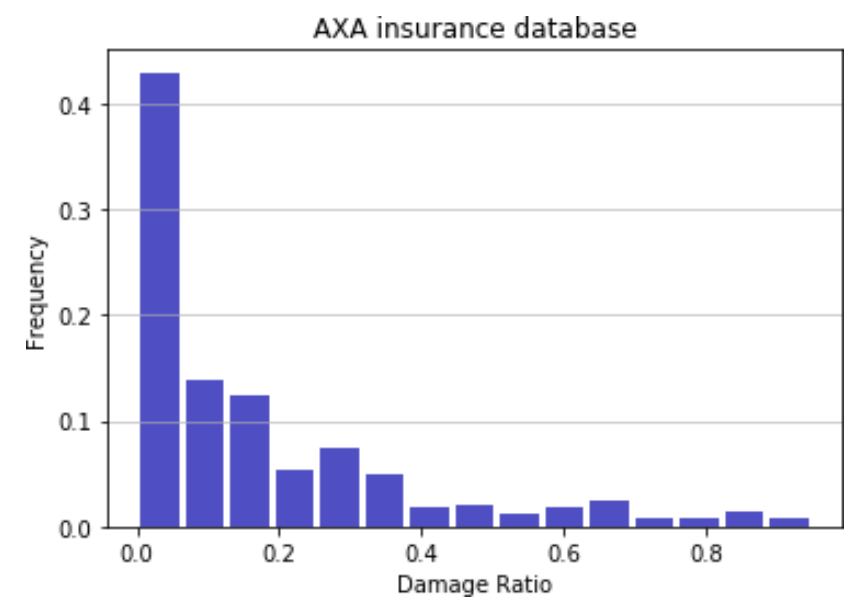

Figure 1. Damage ratio histogram for insurance claims data in the region.

than 0.5 (considerable damages), $30 \%$ had DR higher than 0.2 (medium damages), and $49 \%$ had low damages. This is a typical distribution for damage claims (see for example Fuchs et al., 2019).

The damage curve is an important tool in risk assessment science related to the vulnerability of structures (Pistrika and Jonkman, 2010; Englhardt et al., 2019). From the structural point of view, damage curves depend on the construction materials that buildings are made of (Huizinga, et al., 2017; Postacchini et al., 2019; Masoomi et al., 2019). Damage curves also depend on construction methods, codes, and building layout, including the distance between buildings (Suppasri et al., 2013; Jansen et al., 2020; Masoomi et al., 2019). The current paper focuses on one-two-storey masonry buildings under the effect of storm surge and wave forces produced by an extratropical storm in northwest France. The Xynthia storm provided a rare dataset of empirical measured damage from coastal flooding in a European country. Similar analysis of damage from other storms with different return periods in the same region would help to reduce uncertainty (Breilh et al., 2014; Bulteau et al., 2015), but for now no other claims data are available.

In flood risk assessment, the relation between damage and hazard is quantified by fragility curves and damage curves. The difference between these two is that fragility curves express the probability that a structure is damaged to a specified structural state (Tsubaki et al., 2016), while damage curves instead assess the cost of damage incurred by flooding of a given structure (Englhardt et al., 2019; Huizinga et al., 2017). For both cases it is important to highlight the fact that these curves usually rely on the flood depth alone to quantify the hazard (Pregnolato et al., 2015), while there are fewer studies that attempt to represent the hazard by other quantities like the flow velocity, significant wave height, or wave force (Kreibich et al., 2009; De Risi et al., 2017). For instance, Tomiczek et al. (2017) related the flow velocity to the struc- ture damage state (DS) in New Jersey for Hurricane Sandy. In the present study we relate eight different hydrodynamic variables to the damage ratio coming from insurance claims following extratropical storm Xynthia.

Damage curves are commonly developed by the correlation of field or laboratory measurements of damage, with numerical simulations of hazard level. Tsubaki et al. (2016) measured railway embankment and ballast scour in the field and correlated this damage with flood overflow surcharge calculated by a hydrodynamic flood simulation. Englhardt et al. (2019) and Huizinga et al. (2017) used big-data analytics to correlate tabulated damages with estimated flood levels over a large scale. Pregnolato et al. (2015) showed that most damage functions are based on flood depth alone, though a few also consider flow speed (De Risi et al., 2017; Jansen et al., 2020) or flood duration. The water depth is an important variable since it accounts for the static forces that act on a structure. Nevertheless, in storm events, structures close to the coast at a foreshore/backshore can be subjected to dynamical forces like the action of flow and waves (Kreibich et al., 2009; Tomiczek et al., 2017). For this reason, in order to consider other possible forces the following hydrodynamic parameters are analysed: water depth $(h)$, flow speed $(v)$, unit discharge $(h v)$, flow momentum flux $\left(\rho h v^{2}\right)$, significant wave height $\left(H_{\text {sig }}\right)$, total water depth $\left(h+H_{\text {sig }}\right)$, wave energy flux $\left(E_{\mathrm{f}}\right)$, and total force $\left(\frac{E_{\mathrm{f}}}{C_{\mathrm{g}}}+\rho h v^{2}\right)$. The wave energy flux is defined via Eq. (1) as in Bricker et al. (2017).

$E_{\mathrm{f}}=\frac{1}{16} \rho g H_{\mathrm{sig}}^{2} C_{\mathrm{g}}$,

where $H_{\text {sig }}(\mathrm{m})$ is the significant wave height, $C_{\mathrm{g}}\left(\mathrm{m} \mathrm{s}^{-1}\right)$ is the wave group velocity, $\rho\left(\mathrm{kg} \mathrm{m}^{-3}\right)$ is the water density, $g$ $\left(\mathrm{m} \mathrm{s}^{-2}\right)$ is the acceleration due to gravity, and $C_{\mathrm{g}}=\sqrt{g h}$ over land where waves impact buildings.

\section{Methods}

Damage curves were developed by hindcasting the hazard with a meteorological model, followed by a hydrodynamic (tides and storm surge) and wave model, and then correlating the resulting flood conditions with claimed damages (Fig. 2).

\subsection{Meteorological model setup and description of the Xynthia storm}

From 23 February 2010 Météo-France recorded a lowpressure front that was forming in the North Atlantic and passed north of Spain on 27 February, with a minimum pressure of $966 \mathrm{hPa}$ (Fig. 3). Early in the morning of 28 February it made landfall on the French coast at the same time that a high astronomical tide was developing, causing a total of 65 casualties in the regions of Vendée and Charente-Maritime and approximately EUR 2.5 billion in damage to agricultural 


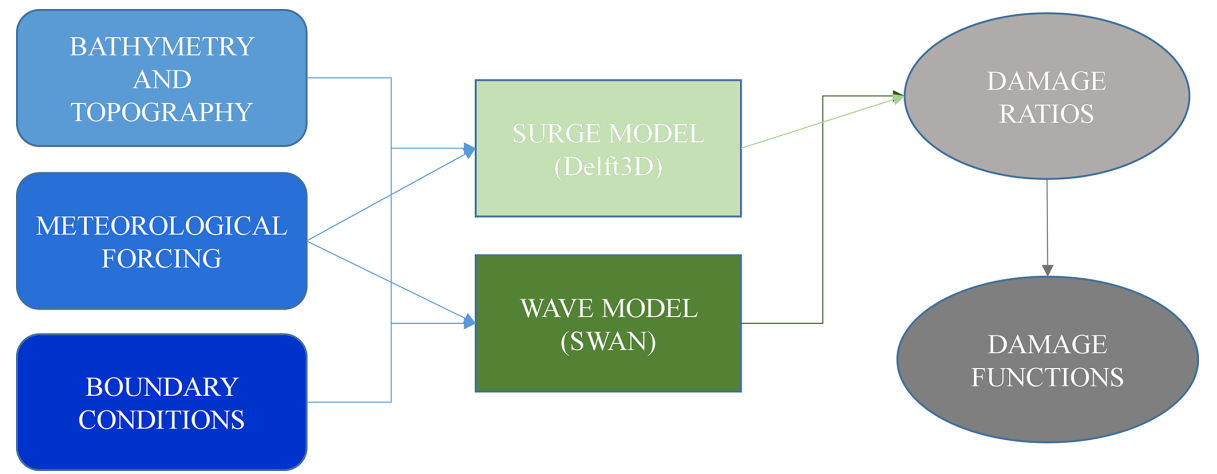

Figure 2. Flow chart of the framework used in development of damage curves.

(oyster farms and mussels) infrastructure, the tourist industry, and residential/commercial zones (Slomp et al., 2010). To generate pressure and wind fields to drive the storm surge model, dynamically downscaled surface meteorological data were generated for the French Atlantic study region (Fig. 3). This contains zonal and meridional winds $10 \mathrm{~m}$ above ground $(u 10, v 10)$ and surface pressures over sea and land, with $3.5 \mathrm{~km}$ spatial resolution and $3 \mathrm{~h}$ temporal resolution. The dynamical downscaling was performed with the regional climate model WRF (Skamarock and Klemp, 2008), based on National Centers for Environmental Prediction (NCEP) Climate Forecast System Reanalysis (CFSR) data (Saha et al., 2010). The regional non-hydrostatic WRF model (version 3.4) simulated 15 February 2010 to 5 March 2010. The initial and lateral boundary conditions are taken from the CFSR reanalysis at $0.5^{\circ}$ resolution, updated every $6 \mathrm{~h}$. The horizontal resolution is $7 \mathrm{~km}$; we use a vertical resolution of 35 sigma levels with a top of atmosphere at $50 \mathrm{hPa}$. The simulation domain was chosen to be wide enough in latitude and longitude for WRF to fully simulate the large-scale atmospheric features of the Xynthia extratropical cyclone. A spinup time of $5 \mathrm{~d}$ was considered in the study to remove spurious effects of the top layer soil moisture adjustment even though most of the analyses here are performed over the ocean. Land surface processes are resolved by using the NOAA land surface model scheme with four soil layers. Numerical schemes used in the WRF simulation to downscale Xynthia data are the multi-scale Kain-Fritsch scheme for convection, the Yonsei University scheme for the planetary boundary layer, the WRF single-moment six-class scheme for microphysics, and the RRTMG scheme for shortwave and longwave radiation. WRF outputs are generated every $3 \mathrm{~h}$.

\subsection{Hydrodynamic model of the Xynthia storm}

In order to capture the hydrodynamic storm characteristics, a regional model domain over the Atlantic Spanish and French coasts was built. As shown schematically in Fig. 2, Delft3D calculates non-steady flow phenomena that result from tidal and meteorological forcing on a rectilinear or a curvilinear grid (Deltares, 2021). At the same time, and coupled with Delft3D, a spectral wave model (SWAN) calculates significant wave height and period fields. Delft3D and SWAN were used to hindcast the physical forcing at the locations of all claims in the database. Afterwards, a probability standardized normal distribution function as proposed by Suppasri et al. (2013) was used to develop damage curves by correlating claimed damage with a variety of hydrodynamic forcing variables. To conserve computational resources and reduce computation time, domain decomposition (two-way hydrodynamic nesting) was implemented with grids of resolution of $\sim 2 \mathrm{~km}$ over the open ocean, $\sim 400 \mathrm{~m}$ close to the study area, and $\sim 80 \mathrm{~m}$ over the area of claims data (Fig. 3 ).

\subsubsection{Topography and bathymetry}

We use two types of topography datasets: a global dataset for the bathymetry/topography (GEBCO, 2020, which is based on SRTM 15+ v2 over land), and a higher-resolution bathymetry (MNT HOMONIM project) and topography (IGN). Additionally, a survey of flood wall height was performed during August 2020 in order to include flood walls as thin weirs inside the Delft3D model and in this way overcome the fact that inside the high-resolution $5 \mathrm{~m}$ topography, these structures are not represented, as suggested by Bertin et al. (2014). Luppichini et al. (2019) and Ettritcha et al. (2018) found that the quality of bathymetry and topography data has a large effect on estimation of the hazard, and Brussee et al. (2021) similarly found topography data quality affects resulting damage estimates. In order to investigate the effect of the quality of topographic and bathymetric data on the resulting damage functions, three scenarios are considered in our work (Table 1).

\subsection{Hydrodynamic and wave model setup}

Delft3D was coupled together with SWAN in order to hindcast storm tide and waves. Model boundary conditions consisted of astronomical tidal water elevations from the Global Tide and Surge Model (GTSM) of Muis et al. (2016) for the 


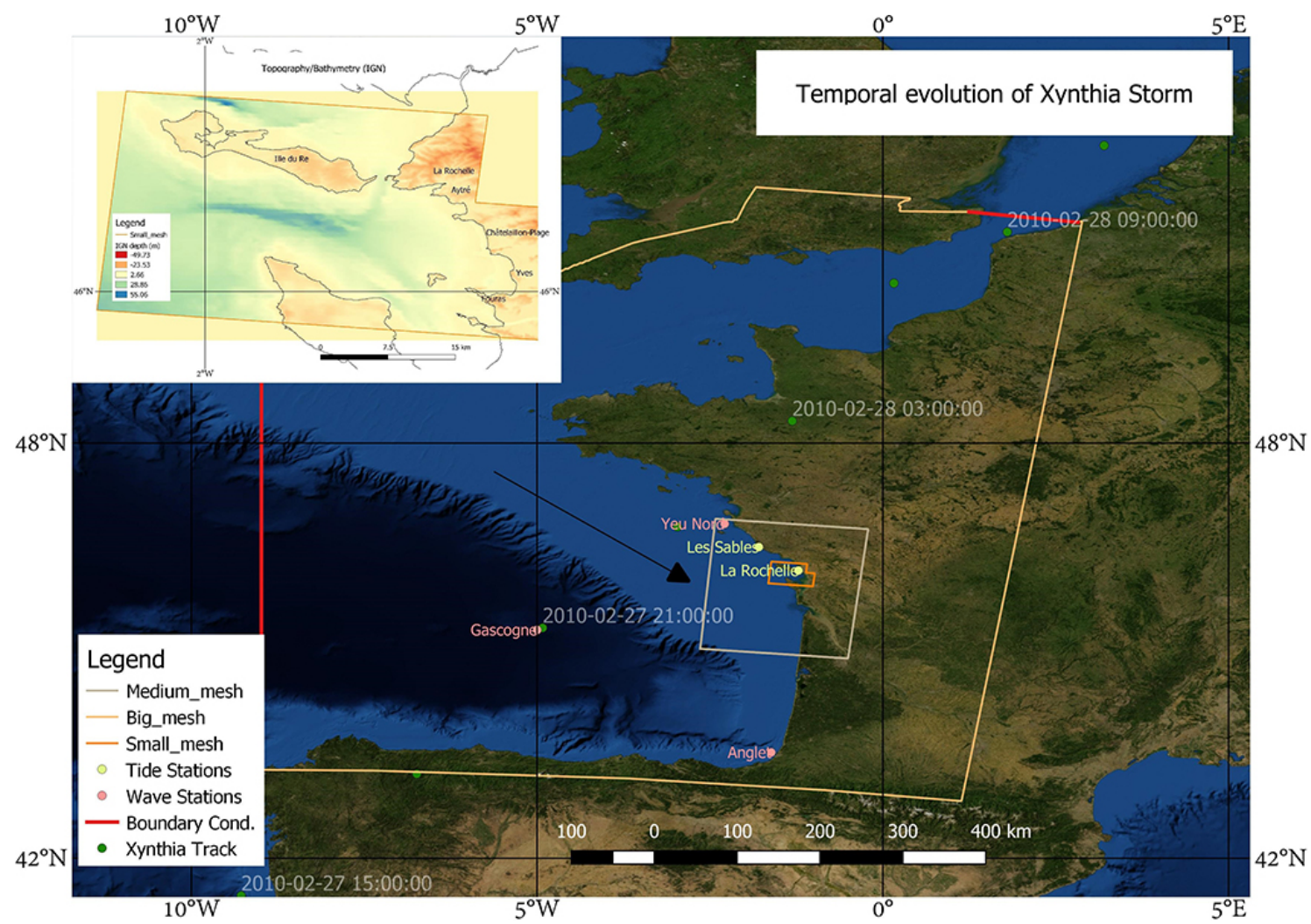

Figure 3. Domain decomposition with three nested grids running in parallel. The centre of the Xynthia storm is shown as a triangle at the time of minimum atmospheric pressure of $966 \mathrm{hPa}$ on 27 February 2010 at 21:00:00 (Extreme Wind Storm Catalogue). Topographic map inset covers the smallest domain shown on the large map. Satellite image by OpenLayers - QGIS.

Table 1. Case studies for investigating sensitivity of model result to digital elevation model (DEM) resolution.

\begin{tabular}{llll}
\hline Item & Low resolution (a) & High resolution $(\mathrm{b})$ & High resolution + structures $(\mathrm{c})$ \\
\hline Topography & GEBCO $(500 \mathrm{~m})$ & IGN $(5 \mathrm{~m})$ & $\begin{array}{l}\text { IGN }(5 \mathrm{~m})+\text { flood walls surveyed } \\
\text { by the authors with an RTK-GPS }\end{array}$ \\
\hline Bathymetry & GEBCO $(500 \mathrm{~m})$ & $\begin{array}{l}\text { GEBCO }(500 \mathrm{~m}) \text { in deep water } \\
+ \text { MNT }(100 \mathrm{~m}) \text { near shore }\end{array}$ & $\begin{array}{l}\text { GEBCO }(500 \mathrm{~m}) \text { in deep water } \\
+ \text { MNT }(100 \mathrm{~m}) \text { near shore }\end{array}$ \\
\hline
\end{tabular}

period from 20 February until 1 March 2010. The hydrodynamic model was run with a computational time step of $30 \mathrm{~s}$ and a uniform Manning $n$ of 0.025 . The air-sea drag coefficient of Smith and Banke (1975) was used. Other model parameters retained their default settings.

\subsection{Hydrodynamic and wave model validation}

\subsubsection{Storm tide validation}

The hydrodynamic model was run from 20 February until 1 March 2010, the duration of the meteorological forcing data, with GTSM astronomical tide boundary conditions. For validation, three accuracy indicators are assessed: root mean square error (RMSE, Eq. 3), relative root square error
(RRSE, Eq. 4), and the Pearson correlation coefficient ( $\rho$, Eq. 5).

$$
\begin{aligned}
\mathrm{RMSE} & =\sqrt{\frac{\sum_{1}^{T}\left(y^{\prime}-y\right)^{2}}{T}}, \\
\mathrm{RRSE} & =\sqrt{\frac{\sum_{1}^{T}\left(y^{\prime}-y\right)^{2}}{\sum_{1}^{T}(y-\bar{y})^{2}}}, \bar{y}=\frac{\sum_{1}^{T} y}{T} \\
\rho_{y, y^{\prime}} & =\frac{\operatorname{cov}\left(y, y^{\prime}\right)}{\sigma_{y} \sigma_{y^{\prime}}},
\end{aligned}
$$


Table 2. Goodness of fit for water level and wave measurements compared with the results of Delft3D-SWAN.

\begin{tabular}{lrrr}
\hline Station & RMSE & $\begin{array}{r}\rho \\
(\mathrm{m})\end{array}$ & RRSE \\
\hline Gascogne & 1.5434 & 0.6228 & 0.10679 \\
Yeu Nord & 0.8668 & 0.6985 & 0.1116 \\
Les Sables-d'Olonne & 0.4959 & 0.9197 & 0.1381 \\
La Rochelle & 0.4991 & 0.9157 & 0.1374 \\
\hline
\end{tabular}

where $y^{\prime}$ is the predicted value, $y$ is the actual value and $\bar{y}$ is the average of the actual values to predict, $T$ is the number of values, and $\sigma$ indicates the standard deviation.

After $2 \mathrm{~d}$ of model spin-up (the time required for the model to correct the assigned initial condition), the comparison between the observed water levels from the French Naval Hydrographic and Oceanographic Service (SHOM)Coriolis tide gauges (http://www.coriolis.eu.org/, last access: 1 May 2021) and modelled water levels from Delft3D during the whole simulation is acceptable (Fig. 4) according to the results for the goodness-of-fit indices in Table 2. If we compare these values with typical values in the literature such as Matte et al. (2014) or Tranchant et al. (2021), we observe the current modelled water levels fit the observations well. Note that the Les Sables-d'Olonne gauge failed at the peak of the storm (on 28 February 2010 at 03:00:00), so a data point is missing in the observations at that time. At La Rochelle the difference between the observed and modelled water level is only $36 \mathrm{~cm}$ at peak storm tide.

\subsubsection{Wave model validation}

The wave model was validated against data from the SHOMCoriolis operational oceanography centre (http://www. coriolis.eu.org/About-Coriolis, last access: 1 May 2021) in Fig. 5. Important to mention is that the data available at the buoys stations do not include the significant wave height; therefore, the swell height was extracted to compare the results from Delft3D-SWAN. The uncertainty produced by the meteorological downscaling by means of the WRF model in the hindcast of the winds can add errors in the results. Unfortunately, no more meteorological information is available. If we again compare the indices from Table 2 to those found in the literature such as Baron-Hyppolite et al. (2019), we find comparable goodness of fit between modelled and measured waves.

\subsection{Damage curves}

Damage curves express the amount of damage experienced by a structure, relative to the structure's total insured value. The cumulative distribution function, in terms of the standardized normal distribution function with the damages (Suppasri et al., 2013; Thapa et al., 2020; Sihombing and
Torbol, 2016), is shown in Eq. (2).

$P(x)=\Phi\left[\frac{x-\mu}{\sigma}\right]$,

where $P(x)$ is the cumulative probability of the damage ratio with values between 0 and 1 , and $x$ is the hydrodynamic variable, $\Phi$ is the standardized normal distribution, $\mu$ is the median, and $\sigma$ is the standard deviation (Tsubaki et al., 2016). It is also very common to express Eq. (1) as a logarithmic function in order to easily obtain the parameters of the distribution with least squares fitting as proposed by Suppasri et al. (2013). In the present paper, the parameters are assessed using the Lmoments package within the open-source program R. In this way, it is possible to relate different hydrodynamic variables with the damage ratio. From the 423 claims data within our domain, approximately 185 are from Île de Ré, and the remaining 238 are from the towns of La Rochelle, Aytré, Yves, Châtelaillon-Plage, and Fouras. At each claim location, the maximum of each hydrodynamic variable was extracted, and from this the damage curves were compiled.

\section{Results}

After determining the model hydrodynamic and wave results (Fig. 6) at the location of each claim location, the data were subdivided into 10 categories according to damage ratio level, and box-whisker plots were built to display the entire dataset and analyse the trend of the data (Appendix A). Among the flow-only variables, the unit discharge $(h v)$ appears to have the clearest trend and least scatter. From the variables related to both flow and waves, the total force $\left(\frac{E_{\mathrm{f}}}{C_{\mathrm{g}}}+\rho h v^{2}\right)$ appears to have the clearest trend and correlation with the damage ratio.

\subsection{Damage curves from each digital elevation model}

In order to build damage curves with Eq. (2), the median values are extracted from the boxplots of Appendix A (Figs. A1 to A3) for each variable. In Fig. 7 the damage curves for each hydrodynamic parameter are displayed as three lines, one for each digital elevation model of Table 1 . Similar to Reese and Ramsay (2010), we find that more than $90 \%$ of the damage occurs in the first $5 \mathrm{~m}$ of flood depth.

Table 3 shows that among the hydrodynamic parameters related only to storm surge, the water depth best fits Eq. (2), with the lowest errors (RMSE and RRSE) and the highest Pearson coefficient $(\rho)$. Among the combined surge and wave parameters, the best correlation is the total (flow plus wave) force, using the IGN + structures topography and bathymetry (Table 3 ). This is related to the fact that this digital elevation model includes thin flood walls that contribute to protection, and which can substantially modify the flow and wave fields over land. 


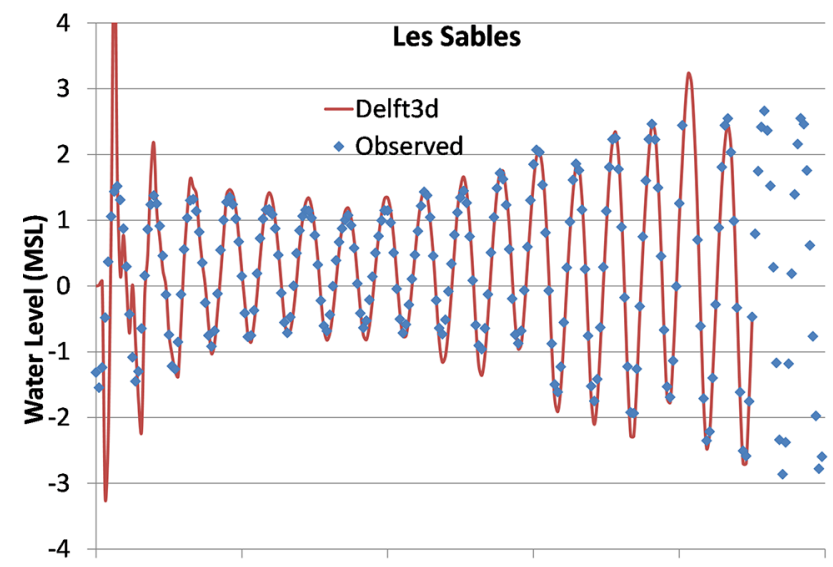

20/02/2010 22/02/2010 24/02/2010 26/02/2010 28/02/2010 02/03/2010

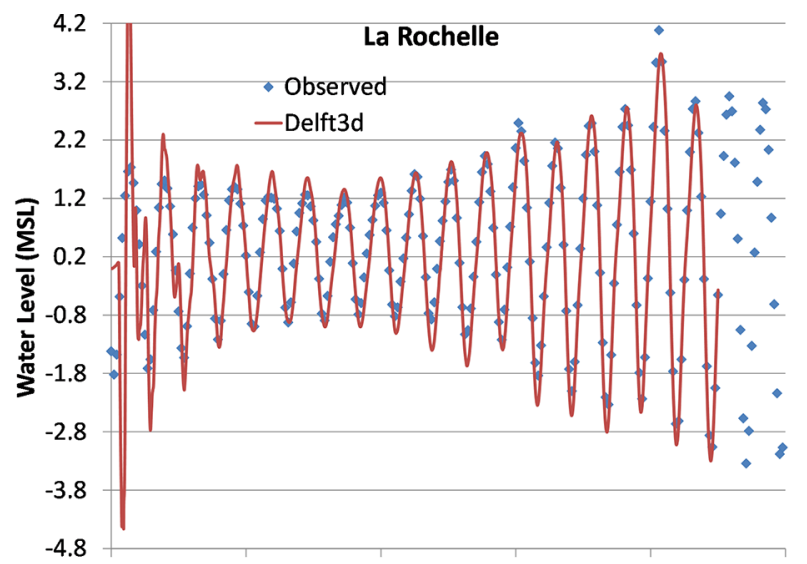

$20 / 02 / 201022 / 02 / 2010$ 24/02/2010 26/02/2010 28/02/2010 02/03/2010

Figure 4. Observed and modelled tide at La Rochelle and Les Sables-d'Olonne. Note that during the peak of the storm tide at Les Sablesd'Olonne, the tide measuring gauge was out of operation, resulting in a missing data point in that data series.
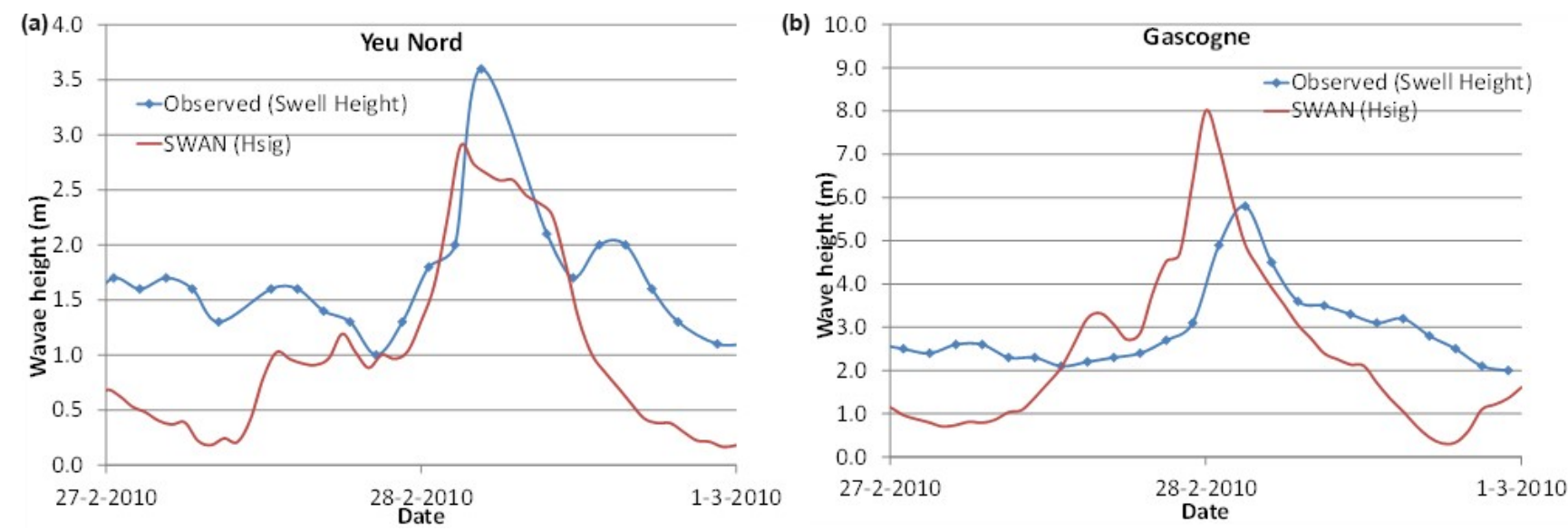

Figure 5. Deep water buoys of Yeu Nord (a) and Gascogne (b). In the first case the buoy is located close by an island of the same name. The second is located in the open ocean almost in the middle of the Bay of Biscay.

In Appendix B a comparison to two other typical distribution functions is carried out. It can be seen that the gamma and generalized normal (GNO) distributions have similar goodness-of-fit indicators, while the log-normal distribution performs slightly worse overall. An analysis on the uncertainty due to the statistical distribution selection or the inclusion of properties with no damages can be found in Fuchs et al. (2019). Another source of uncertainty, in addition of the selected statistical distribution, is the parameter fitting method (Diaz-Loaiza, 2015). Typical methods for this purpose include Lmoments, maximum spacing estimation, maximum likelihood, moment method, and least squares method (Oosterbaan, 1994).

\section{Discussion}

The present paper considered the influence of flow-only variables $\left(h, v, h v, \rho h v^{2}\right)$ and combined flow-wave parameters $\left(H_{\text {sig }} h+H_{\text {sig }}, E_{\mathrm{f}}, \frac{E_{\mathrm{f}}}{C_{\mathrm{g}}}+\rho h v^{2}\right)$. Flow depth and total (flow plus wave) force produce the best fits with analytical functions. Goodness of fit to damage curves improves with quality of the topographic data used (Table 1). However, when applying damage curves in practice, it is important to base predictions off a similar model setup to that used when calculating the damage curves in the first place (Brussee et al., 2021). For example, if damage curves are built using coarse topography that neglects the presence of thin seawalls (i.e. sheet pile/cantilever walls, or T or L walls), then the buildings protected by these walls might experience more intense hydrodynamic conditions in the simulation than if the walls had been present in the simulation. Since the actual recorded damage does not depend on the model used to calculate 


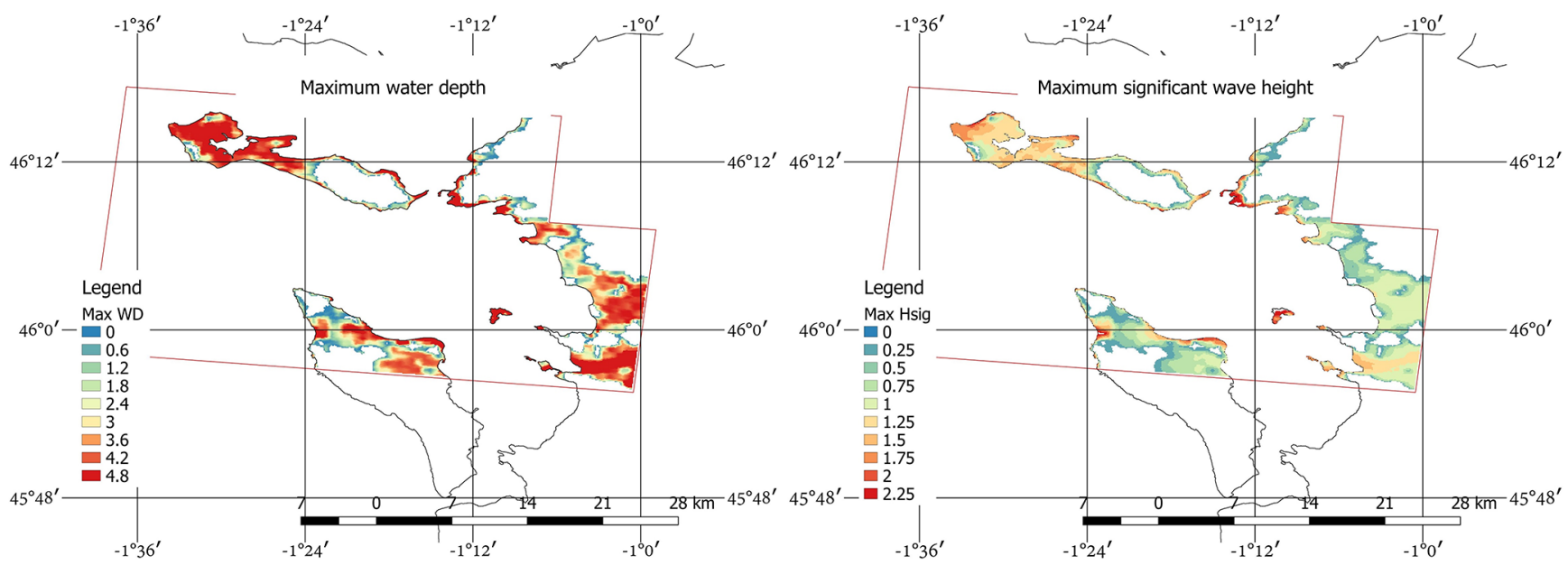

Figure 6. Maximum water level and maximum significant wave height (Hsig) footprints for the small model domain (case study area). Water depth and wave height are in units of metres. The purple rectangle indicates the limits of the small domain, outside of which data are not shown.

Table 3. Goodness of fit for the flow-only and flow-plus-wave parameters. The best fits for flow-only parameters are indicated in bold, and the best fits for flow-plus-wave parameters are indicated in bold italic.

\begin{tabular}{lrrr|rrr|rrr}
\hline Variable & \multicolumn{3}{c}{ RMSE $(\mathrm{m})$} & & $\rho$ & & \multicolumn{2}{c}{ RRSE } \\
\cline { 2 - 9 } & GEBCO & IGN & $\begin{array}{r}\text { IGN+ } \\
\text { structures }\end{array}$ & GEBCO & IGN & $\begin{array}{r}\text { IGN+ } \\
\text { structures }\end{array}$ & GEBCO & $\begin{array}{r}\text { IGN } \\
\text { IGN+ } \\
\text { structures }\end{array}$ \\
\hline Water depth $(h)$ & 0.1595 & 0.1898 & $\mathbf{0 . 1 4 9 5}$ & 0.8134 & 0.7344 & $\mathbf{0 . 8 3 2 8}$ & 0.1009 & 0.1145 & $\mathbf{0 . 0 9 0 2}$ \\
Flow speed $(\mathrm{v})$ & 0.3586 & 0.2561 & 0.2234 & 0.1284 & 0.5387 & 0.6406 & 0.2268 & 0.1545 & 0.1347 \\
Unit discharge $(h v)$ & 0.3352 & 0.2272 & 0.2120 & 0.2421 & 0.6558 & 0.6744 & 0.2120 & 0.1370 & 0.1278 \\
Flow momentum flux $\left(\rho h v^{2}\right)$ & 0.3542 & 0.2540 & 0.1822 & 0.1314 & 0.5759 & 0.7622 & 0.2136 & 0.1532 & 0.1099 \\
Significant wave height $\left(H_{\text {sig }}\right)$ & 0.2211 & 0.2030 & 0.1600 & 0.6432 & 0.6901 & 0.8066 & 0.1398 & 0.1224 & 0.0965 \\
Total water depth $\left(h+H_{\text {sig }}\right)$ & 0.1767 & 0.2217 & 0.1522 & 0.7575 & 0.6404 & 0.8265 & 0.1117 & 0.1337 & 0.0918 \\
Wave energy flux $\left(E_{\mathrm{f}}\right)$ & 0.2649 & 0.2391 & 0.2307 & 0.5519 & 0.5851 & 0.6510 & 0.1676 & 0.1442 & 0.1391 \\
\hline Total force $\left(\frac{E_{\mathrm{f}}}{C_{\mathrm{g}}}+\rho h v^{2}\right)$ & 0.3307 & 0.2494 & $\mathbf{0 . 1 4 9 9}$ & 0.2396 & 0.5888 & $\mathbf{0 . 8 3 8 7}$ & 0.2092 & 0.1504 & $\mathbf{0 . 0 9 0 4}$ \\
\hline
\end{tabular}

the hydrodynamic forcing conditions, damage curves developed using the coarse-resolution topography will be shifted to the right relative to damage curves generated with the thin flood walls present. If these damage curves generated using a coarse-resolution simulation are then applied for damage prediction by an external user who applies a high-resolution simulation that resolves flood walls, the reduced forcing (due to the presence of these flood walls) will generate a nonconservative result (too little damage), because the damage curves had been generated using forcing data from a simulation where the flood walls had not been present. Therefore, when damage curves are reported in the literature, it is important to quantify how these vary with the topography used in the simulations on which the damage curves are based. However, in the current paper, Fig. 7 shows that damage curves do not vary consistently leftward or rightward as topographic data are improved. This is because the response of forcing to the presence of these walls is more complex than simply re- ducing wave height. If not overflowed, walls reduce damage greatly. However, water depth can be exacerbated in front of walls, and flow can be channelled and intensified along walls, all increasing hydrodynamic forcing in some locations, preventing a simple relation between topographic resolution and damage curve robustness.

In addition to the general sensitivity of damage curves to topographic data quality, the damage curves displayed in Fig. 7 do not consider certain physical wave-driven phenomena such as wave overtopping of structures (Lashley et al., 2020a; Ke et al., 2021) or infragravity waves generated by waves breaking in shallow water (Roeber and Bricker, 2015). For instance Lashley et al. (2019) discussed the importance of dike overtopping due to infragravity waves on nearshore developments that can induce wave-driven coastal inundation. The wave model used here, SWAN, does not include infragravity waves, nor does the combined Delft3D-SWAN flow-wave model simulate wave overtopping of dikes, possi- 

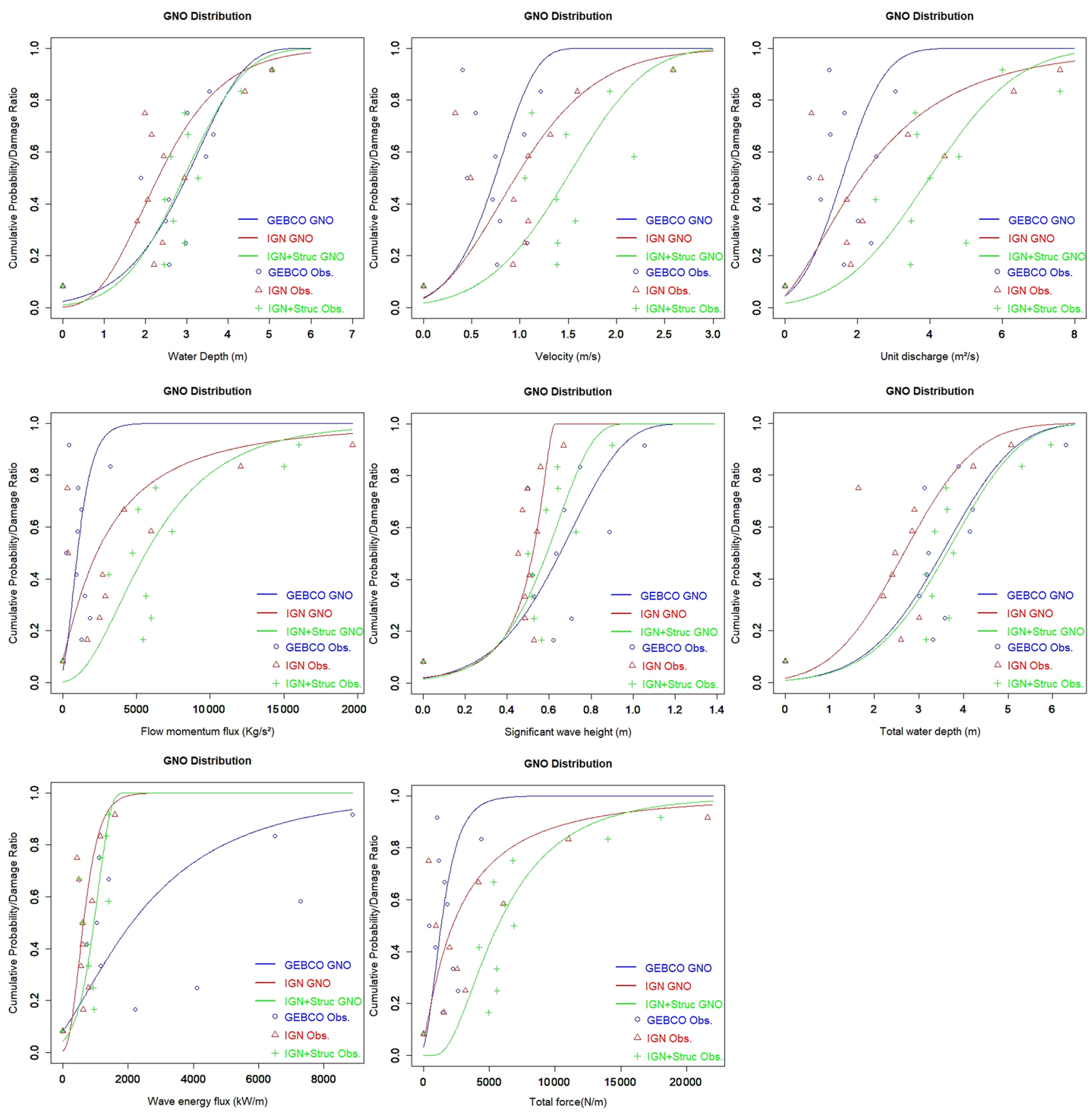

Figure 7. Damage curves for the surge and wave variables $\left(h, v, h v, \rho h v^{2}, H_{\text {sig }}, h+H_{\text {sig }}, E_{\mathrm{f}}, \frac{E_{\mathrm{f}}}{C_{\mathrm{g}}}+\rho h v^{2}\right)$ and different bathymetry/topography conditions (Table 1). Markers indicate the observed data and lines the fitted statistical distributions.

bly leading to an underestimation of the hydrodynamic forces on buildings, which would affect the resulting damage functions. However, consideration of wave overtopping and infragravity effects requires either phase-resolving wave simulations or empirical relations specific to the local topography (Lashley et al., 2020b), though this is beyond the scope of the current study and is similarly neglected by most other large- scale inundation studies (i.e., Sebastian et al., 2014; Kress et al., 2016; Kowaleski et al., 2020). Nonetheless, the effect of infragravity oscillations and wave overtopping on resulting damage is an important item for future research.

Another important factor mentioned by Bertin et al. (2015) was the particular track direction of the storm that for the Xynthia event induced a young sea state, enhancing the 
surface stress, and adding up to $40 \mathrm{~cm}$ to the theoretical surge and tide of their model. The uncertainty and variability within this methodology can be explained by two factors: (1) the hydrodynamic modelling, and consequently uncertainty in the hydrodynamic variables, and (2) uncertainty in the claims data. Regarding the first point, there is a trend that indicates that better topography/bathymetry data give hydrodynamic variables that correlate better with the damage ratio. This is because higher-resolution data generally more accurately reproduce the actual flood conditions (Luppichini et al., 2019; Ettritcha et al., 2018). Damage curves developed with a better representation of the topography (IGN + structures) improve the accuracy indicators (Table 3), though scatter in the data themselves (Figs. A1, A2 or A3) is large for all topographies. This first point is also related to the mesh resolution and the roughness coefficients used. The second point deals with the quality of the damage ratio data. It is known that insurance claims can sometimes be subject to fraud or information distortion. In addition, variables related to the vulnerability of the assets like the construction characteristics, the materials, the quality, and the age of the structures (Paprotny et al., 2021) play important roles in determining whether a particular hydrodynamic is related to damage. This adds a degree of complexity to the analysis. Finally, it is worth mentioning that if more detailed information from the claims data is available (like structure type, number of floors, and damage stage), then a more detailed fragility functions can be generated instead of the bulk damage functions determined here.

\section{Conclusions}

Insurance claims data facilitated generation of damage curves for structures located in La Rochelle and surroundings. This provides valuable information for predicting future damages that can be expected from an extratropical storm strike on the French Atlantic coast. In the present study, the hydrodynamic variables that correlated best with the damage ratio are the flow depth and the total (flow plus wave) force for the flow-only and flow-plus-wave-related variables respectively. In addition to the sensitivity of results to resolution of the topographic and bathymetric data, the inclusion of thin flood walls via a land survey carried out by the authors also had a significant effect on the damage functions generated. This is important to note, as thin steel or concrete structures like flood walls are typically only a few decimetres thick and therefore do not appear in digital elevation models. The effect of these thin structures on the resulting damage functions shows the importance of locally sourcing elevation data for the thin structures that are present when conducting risk analyses for coastal regions. However it is imperative to keep in mind agreement between the simulations used for developing the damage relations in the first place and those where the damage relations are applied for further risk analysis. 


\section{Appendix A}

Whisker plots from which damage curves are developed are shown in Figs. A1, A2, and A3. Digital elevation models are as described in Table 1. The damage curves of Fig. 7 use the median values (red lines) from each of the figures in this appendix.
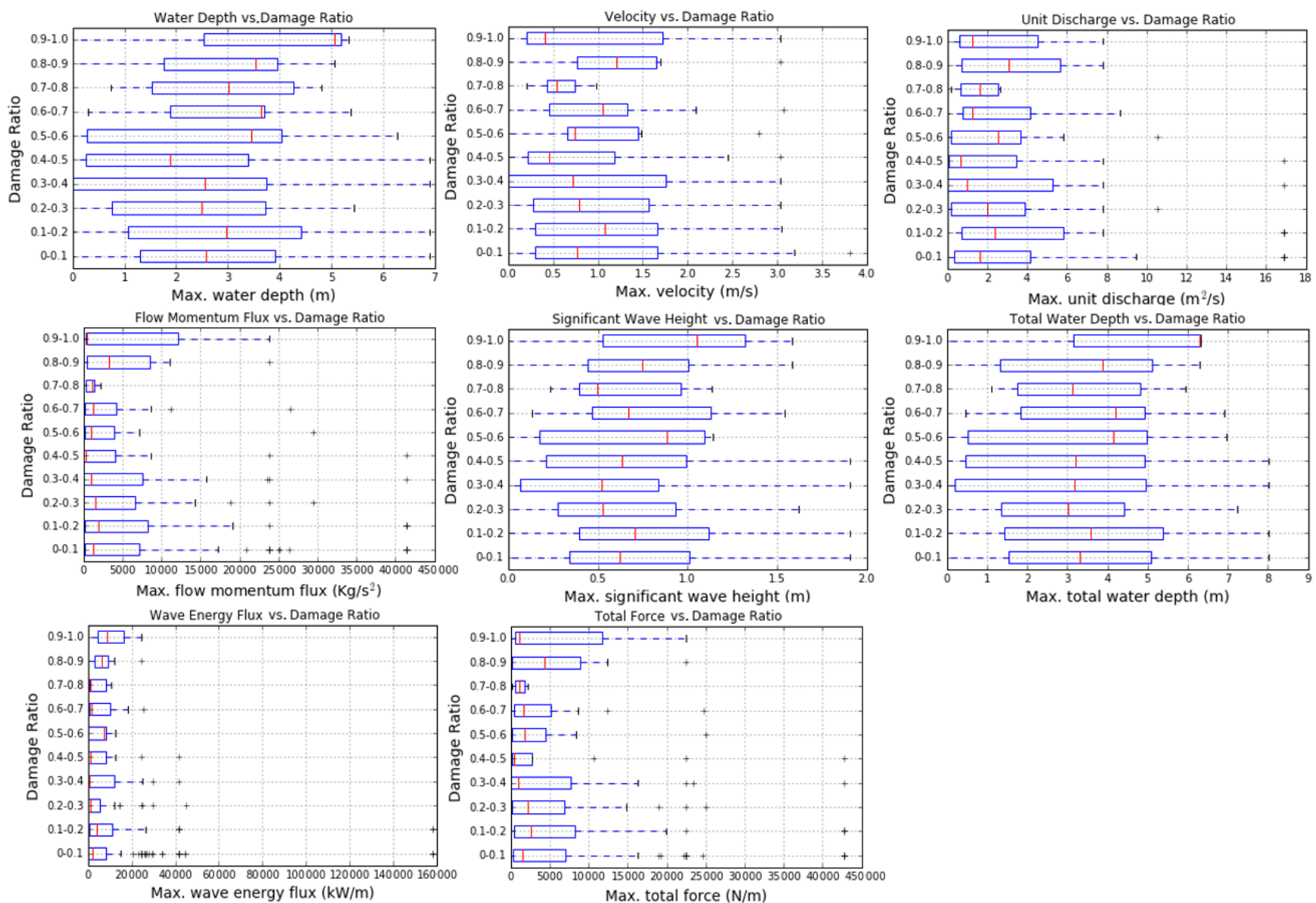

Figure A1. Box-whisker plots for the variables $\left(h, v, h v, \rho h v^{2}, H_{\mathrm{sig}}, h+H_{\mathrm{sig}}, E_{\mathrm{f}}, \frac{E_{\mathrm{f}}}{C_{\mathrm{g}}}+\rho h v^{2}\right)$ with the GEBCO DEM. 

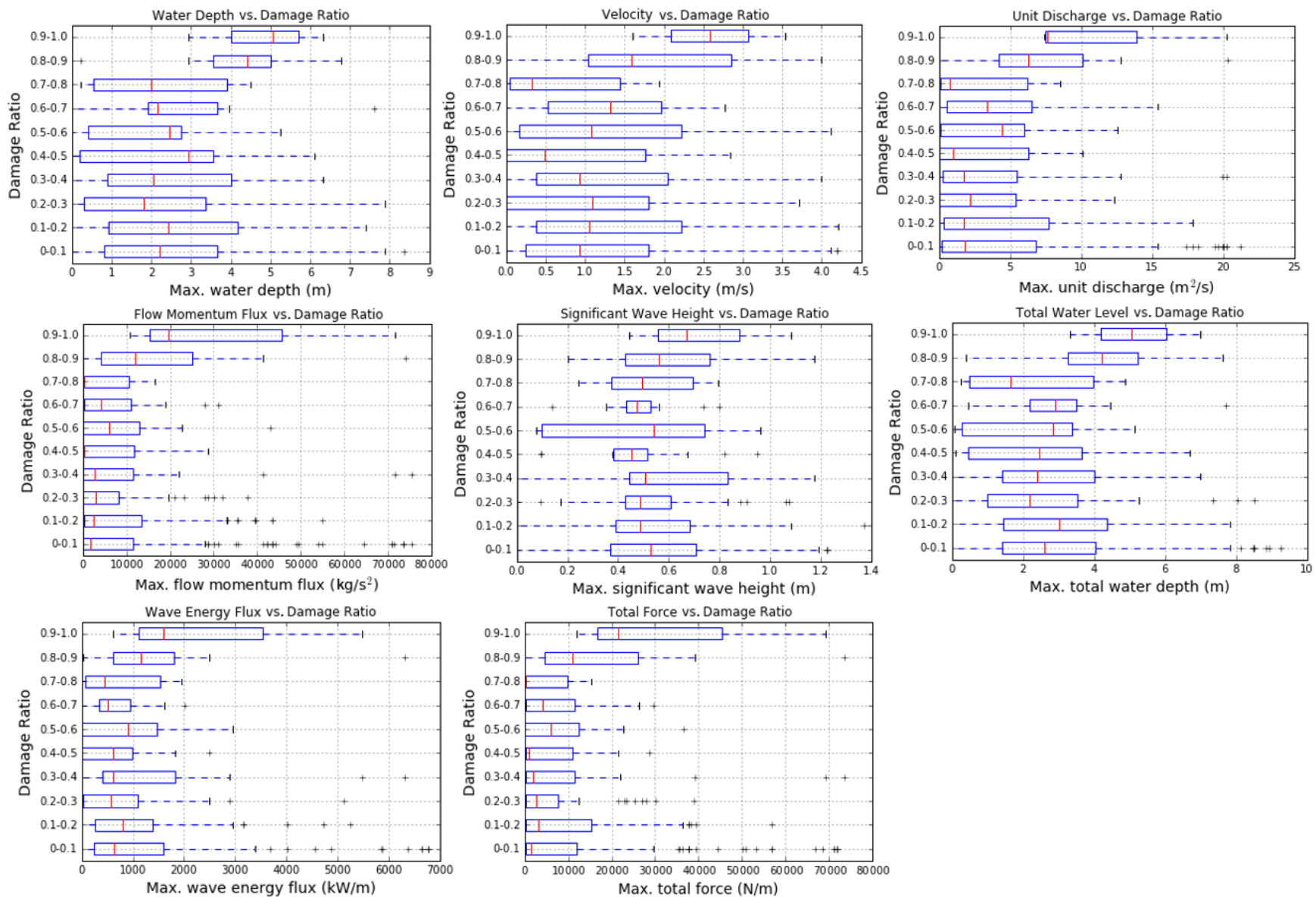

Figure A2. Box-whisker plots for the variables $\left(h, v, h v, \rho h v^{2}, H_{\mathrm{sig}}, h+H_{\mathrm{sig}}, E_{\mathrm{f}}, \frac{E_{\mathrm{f}}}{C_{\mathrm{g}}}+\rho h v^{2}\right)$ with the IGN DEM. 

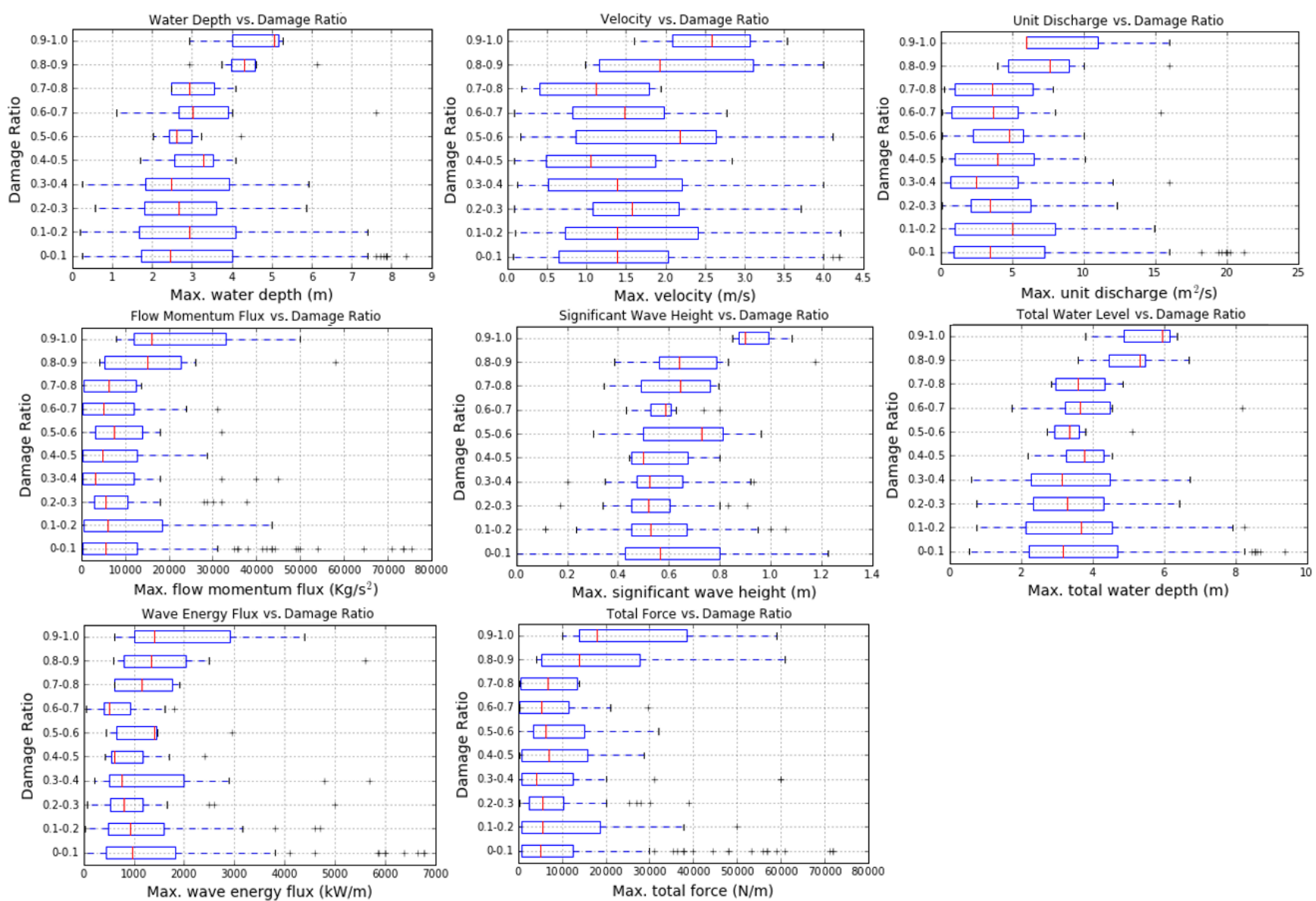

Figure A3. Box-whisker plots for the variables $\left(h, v, h v, \rho h v^{2}, H_{\text {sig }}, h+H_{\mathrm{sig}}, E_{\mathrm{f}}, \frac{E_{\mathrm{f}}}{C_{\mathrm{g}}}+\rho h v^{2}\right)$ with the IGN + structures DEM. 


\section{Appendix B}

Probability distribution comparison for the bathymetry/topography of IGN + structures.
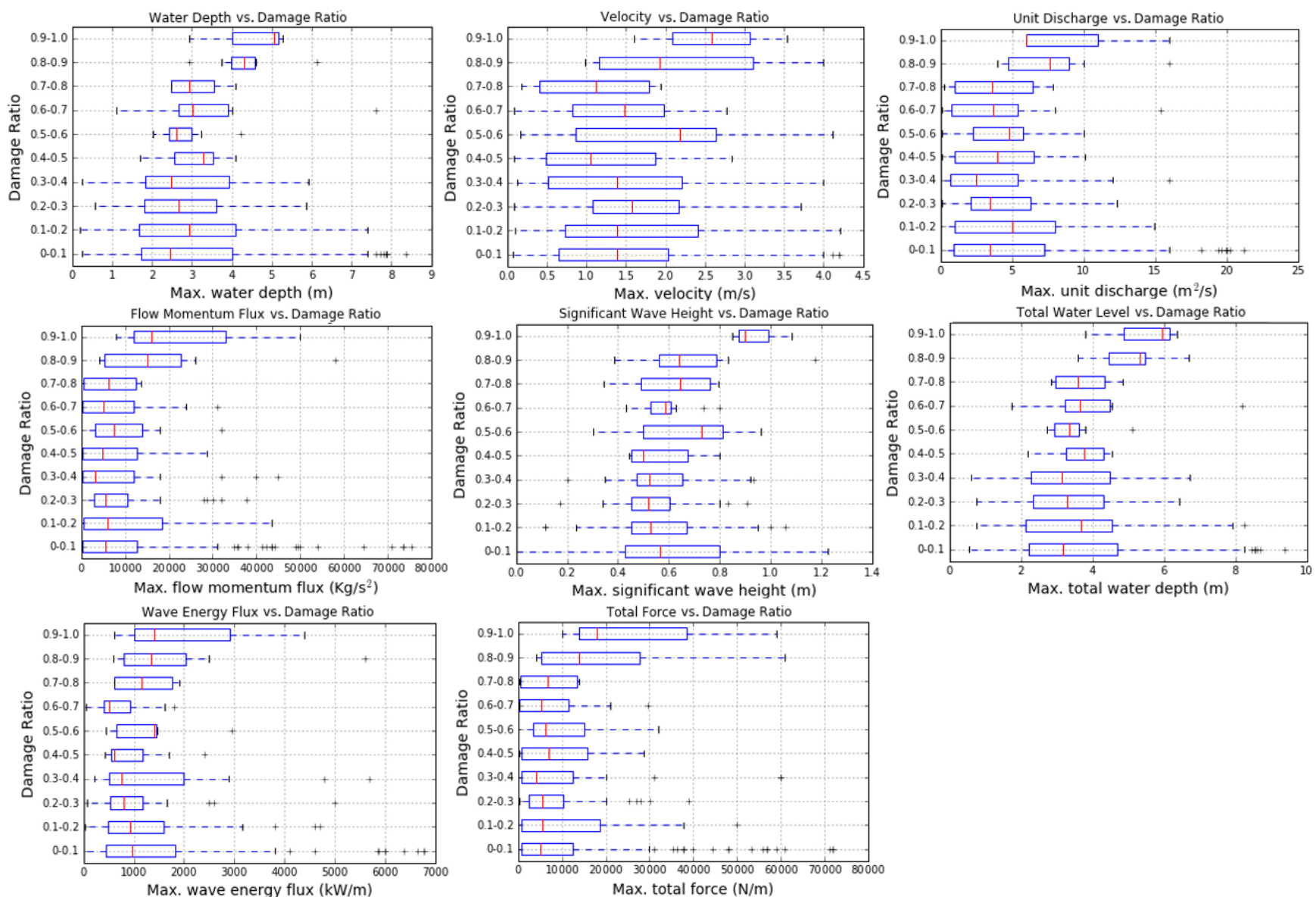

Figure B1. Comparison of three typical statistical distributions used for damage function development. The points correspond to the observed data and lines the different statistical distributions.

Table B1. Goodness-of-fit indices for the gamma, log-normal, and generalized normal statistical distributions. The best fits for flow-only parameters are indicated in bold, and the best fits for flow-plus-wave parameters are indicated in bold italic.

\begin{tabular}{lrrr|rrr|rrr}
\hline Variable & \multicolumn{3}{c}{ RMSE $(\mathrm{m})$} & & \multicolumn{2}{c}{$\rho$} & & \multicolumn{2}{c}{ RRSE } \\
\cline { 2 - 9 } & Gamma & Log normal & GNO & Gamma & Log normal & GNO & Gamma & Log normal & GNO \\
\hline Water depth $(\mathrm{h})$ & 0.1574 & 0.2290 & $\mathbf{0 . 1 4 9 5}$ & 0.8256 & 0.7722 & $\mathbf{0 . 8 3 2 8}$ & 0.0949 & 0.1381 & $\mathbf{0 . 0 9 0 2}$ \\
Flow speed $(\mathrm{v})$ & 0.2306 & 0.2802 & $\mathbf{0 . 2 2 3 4}$ & 0.6180 & 0.6087 & $\mathbf{0 . 6 4 0 6}$ & 0.1390 & 0.1690 & $\mathbf{0 . 1 3 4 7}$ \\
Unit discharge $(h v)$ & 0.2150 & 0.2440 & $\mathbf{0 . 2 1 2 0}$ & 0.6704 & $\mathbf{0 . 7 2 4 4}$ & 0.6744 & 0.1296 & 0.1471 & $\mathbf{0 . 1 2 7 8}$ \\
Flow momentum flux $\left(\rho h v^{2}\right)$ & $\mathbf{0 . 1 7 9 0}$ & 0.2341 & 0.1822 & $\mathbf{0 . 7 6 8 6}$ & 0.7591 & 0.7622 & $\mathbf{0 . 1 0 7 9}$ & 0.1412 & 0.1099 \\
Significant wave height $\left(H_{\text {sig }}\right)$ & 0.1719 & 0.2888 & $\mathbf{0 . 1 6 0 0}$ & 0.7987 & 0.6065 & $\mathbf{0 . 8 0 6 6}$ & 0.1037 & 0.1742 & $\mathbf{0 . 0 9 6 5}$ \\
\hline Total water depth $\left(h+H_{\text {sig }}\right)$ & 0.1604 & 0.2453 & $\mathbf{0 . 1 5 2 2}$ & 0.8195 & 0.7582 & $\mathbf{0 . 8 2 6 5}$ & 0.0967 & 0.1479 & $\mathbf{0 . 0 9 1 8}$ \\
\hline Wave energy flux $\left(E_{\mathrm{f}}\right)$ & 0.2522 & 0.2601 & $\mathbf{0 . 2 3 0 7}$ & 0.5774 & $\mathbf{0 . 7 1 3 0}$ & 0.6510 & 0.1521 & 0.1568 & $\mathbf{0 . 1 3 9 1}$ \\
\hline Total force $\left(\frac{E_{\mathrm{f}}}{C_{\mathrm{g}}}+\rho h v^{2}\right)$ & $\mathbf{0 . 1 4 6 2}$ & 0.2318 & 0.1499 & $\mathbf{0 . 8 4 1 0}$ & 0.7713 & 0.8387 & $\mathbf{0 . 0 8 8 2}$ & 0.1398 & 0.0904 \\
\hline
\end{tabular}


Data availability. Data will be available after publication on the data repository of TU Delft at https://doi.org/10.4121/16713340 (Diaz Loaiza, 2022) as the AXA Xynthia storm research project.

Author contributions. The present paper is based on the postdoctoral research of MADL on the research project INFRA. MADL, $\mathrm{JB}, \mathrm{RM}, \mathrm{TD}$, and RR conceptualized the study and maintained meetings of progress for the project. MADL made the calculations and wrote the manuscript. JB and SJ provided repeated feedback on the manuscript.

Competing interests. The contact author has declared that neither they nor their co-authors have any competing interests.

Disclaimer. Publisher's note: Copernicus Publications remains neutral with regard to jurisdictional claims in published maps and institutional affiliations.

Acknowledgements. This work is funded by the AXA Joint Research Initiative (JRI) project INFRA: Integrated Flood Risk Assessment. A special acknowledgement is due to Adri Mourits from Deltares for the help provided with the Delft3D debugging and to Christopher Lashley for the help during the field trip in Île de Ré and surroundings during August 2020.

Financial support. This research has been supported by the AXA Research Fund (AXA Joint Research Initiative (JRI) project INFRA: Integrated Flood Risk Assessment).

Review statement. This paper was edited by Sven Fuchs and reviewed by Bret Webb and two anonymous referees.

\section{References}

Baron-Hyppolite, C., Lashley, C. H., Garzon, J., Miesse, T., Ferreira, C., and Bricker, J. D.: Comparison of Implicit and Explicit Vegetation Representations in SWAN Hindcasting Wave Dissipation by Coastal Wetlands in Chesapeake Bay, Geosciences, 9, 8, https://doi.org/10.3390/geosciences9010008, 2019.

Bertin, X., Li, K., Roland, A., Zhang, Y. J., Breilh, J. F., and Chaumillon, E.: A modeling-based analysis of the flooding associated with Xynthia, central Bay of Biscay, Coast. Eng., 94, 80-89, 2014.

Bertin, X., Li, K., Roland, A., and Bidlot, J. R.: The contributions of short-waves in storm surges: two case studies in the Bay of Biscay, Cont. Shelf Res., 96, 1-15, 2015.

Breilh, J.-F., Bertin, X., Chaumillon, E., Giloy, N., and Sauzeau, T.: How frequent is storm-induced flooding in the central part of the Bay of Biscay?, Global Planet. Change, 122, 161-175, 2014.
Bricker, J., Esteban, M., Takagi, H., and Roeber, V.: Economic feasibility of tidal stream and wave power in post-Fukushima Japan, Renew. Energ., 114, 32-45, 2017.

Brussee, A. R., Bricker, J. D., De Bruijn, K. M., Verhoeven, G. F., Winsemius, H. C., and Jonkman, S. N.: Impact of hydraulic model resolution and loss of life model modification on flood fatality risk estimation: Case study of the Bommelerwaard, The Netherlands, J. Flood Risk Manag., 14, e12713, https://doi.org/10.1111/jfr3.12713, 2021.

Bulteau, T., Idier, D., Lambert, J., and Garcin, M.: How historical information can improve estimation and prediction of extreme coastal water levels: application to the Xynthia event at La Rochelle (France), Nat. Hazards Earth Syst. Sci., 15, 1135-1147, https://doi.org/10.5194/nhess-15-1135-2015, 2015.

Diaz Loaiza, M. A.: Delft3d and script for Xynthia storm analysis, 4TU Centre for Research Data, [data set], https://doi.org/10.4121/16713340, 2022.

Diaz-Loaiza, M. A.: Drought and flash floods risk assessment methodology, PhD Thesis, Technical University of Catalonia, available at: https://upcommons.upc.edu/handle/2117/95961 (last access: 1 February 2021), 2015.

Deltares: Delft3d user manual, Version: 3.15, SVN Revision: 70333, available at: https://content.oss.deltares.nl/delft3d/ manuals/Delft3D-FLOW_User_Manual.pdf, last access: 1 December 2021.

De Risi, R., Goda, K., Yasuda, T., and Mori, N.: Is flow velocity important in tsunami empirical fragility modeling?, Earth-Sci. Rev., 166, 64-82, 2017.

Chauveau, E., Chadenas, C., Comentale, B., Pottier, P., Blanlœil, A., Feuillet, T., Mercier, D., Pourinet, L., Rollo, N, Tillier, I., and Trouillet, B.: Xynthia: lessons learned from a catastrophe, Environment, Nature and Landscape, https://doi.org/10.4000/cybergeo.28032, 2011.

Englhardt, J., de Moel, H., Huyck, C. K., de Ruiter, M. C., Aerts, J. C. J. H., and Ward, P. J.: Enhancement of largescale flood risk assessments using building-material-based vulnerability curves for an object-based approach in urban and rural areas, Nat. Hazards Earth Syst. Sci., 19, 1703-1722, https://doi.org/10.5194/nhess-19-1703-2019, 2019.

Ettritcha, G., Hardya, A., Bojangb, L., Crossc, D., Buntinga, P., and Brewera, P.: Enhancing digital elevation models for hydraulic modelling using flood frequency detection, Remote Sens. Environ., 217, 506-522, 2018.

Fuchs, S., Heiser, M., Schlögl, M., Zischg, A., Papathoma-Köhle, M., and Keiler, M.: Short communication: A model to predict flood loss in mountain areas, Environ. Modell. Softw., 117, 176180, https://doi.org/10.1016/j.envsoft.2019.03.026, 2019.

GEBCO: The General Bathymetric Chart of the Oceans, available at: https://www.gebco.net/ (last access: 1 May 2021), 2020.

Hatzikyriakou, A. and Lin, N.: Assessing the Vulnerability of Structures and Residential Communities to Storm Surge: An Analysis of Flood Impact during Hurricane Sandy, Front. Built Environ., 4, https://doi.org/10.3389/fbuil.2018.00004, 2018.

Huizinga, J., De Moel, H., and Szewczyk, W.: Global flood depthdamage functions: Methodology and the database with guidelines, Publications Office of the European Union, Luxembourg, https://doi.org/10.2760/16510, 2017.

Jansen, L., Korswagen, P. A., Bricker, J. D., Pasterkamp, S., de Bruijn, K. M., and Jonkman, S. N.: Experimental de- 
termination of pressure coefficients for flood loading of walls of Dutch terraced houses, Eng. Struct., 216, 110647, https://doi.org/10.1016/j.engstruct.2020.110647, 2020.

Ke, Q., Yin, J., Bricker, J. D., Savage, N., Buonomo, E., Ye, Q., Visser, P., Dong, G., Wang, S., Tian, Z., Sun, L., Tuomi, R., and Jonkman, S. N.: An integrated framework of coastal flood modelling under the failures of sea dikes: a case study in Shanghai, Nat. Hazards, 109, 671-703, 2021.

Kowaleski, A. M., Morss, R. E., Ahijevych, D., and Fossell, K. R.: Using a WRF-ADCIRC ensemble and track clustering to investigate storm surge hazards and inundation scenarios associated with Hurricane Irma, Weather Forecast., 35, 1289-1315, 2020.

Kreibich, H., Piroth, K., Seifert, I., Maiwald, H., Kunert, U., Schwarz, J., Merz, B., and Thieken, A. H.: Is flow velocity a significant parameter in flood damage modelling?, Nat. Hazards Earth Syst. Sci., 9, 1679-1692, https://doi.org/10.5194/nhess-91679-2009, 2009.

Kress, M. E., Benimoff, A. I., Fritz, W. J., Thatcher, C. A., Blanton, B. O., and Dzedzits, E.: Modeling and simulation of storm surge on Staten Island to understand inundation mitigation strategies, J. Coastal Res., 76, 149-161, 2016.

Lashley, C., Bertin, X., Roelvink, D., and Arnaud, G.: Contribution of Infragravity Waves to Run-up and Overwash in the Pertuis Breton Embayment (France), Journal of Marine Science and Engineering, 7, 205, https://doi.org/10.3390/jmse7070205, 2019.

Lashley, C. H., Bricker, J. D., van der Meer, J., Altomare, C., and Suzuki, T.: Relative magnitude of infragravity waves at coastal dikes with shallow foreshores: a prediction tool. Journal of Waterway, Port, Coastal, and Ocean Engineering, 146, 04020034, https://doi.org/10.1061/(ASCE)WW.19435460.0000576, 2020a.

Lashley, C. H., Zanuttigh, B., Bricker, J. D., van der Meer, J., Altomare, C., Suzuki, T., Roeber, V., and Oosterlo, P.: Benchmarking of numerical models for wave overtopping at dikes with shallow mildly sloping foreshores: Accuracy versus speed, Environ. Modell. Softw., 130, 104740, https://doi.org/10.1016/j.envsoft.2020.104740, 2020 b.

Luppichini, M., Favalli, M., Isola, I., Nannipieri, L., Giannecchini, R., and Bini, M.: Influence of Topographic Resolution and Accuracy on Hydraulic Channel Flow Simulations: Case Study of the Versilia River (Italy), Remote Sensing, 11, 1630, https://doi.org/10.3390/rs11131630, 2019.

Masoomi, H., van de Lindt, J. W., Do, T. Q., and Webb, B. M.: Combined wind-wave-surge hurricane-induced damage prediction for buildings, J. Struct. Eng., 145, https://doi.org/10.1061/(ASCE)ST.1943-541X.0002241, 2019.

Matte, P., Secretan, Y., and Morin, J.: Temporal and spatial variability of tidal-fluvial dynamics in the St. Lawrence fluvial estuary: An application of nonstationary tidal harmonic analysis, J. Geophys. Res.-Oceans, 119, 5724-5744, https://doi.org/10.1002/2014JC009791, 2014.

Muis, S., Verlaan, M., Winsemius, H., Aerts, J., and Ward, P.: A global reanalysis of storm surges and extreme sea levels, Nat. Commun., 7, 11969, https://doi.org/10.1038/ncomms11969, 2016.

Oosterbaan, R. J.: Frequency and Regression Analysis, chap. 6, in: Drainage Principles and Applications, edited by: Ritzema, $\mathrm{H}$. P., Publ. 16, International Institute for Land Reclamation and
Improvement (ILRI), Wageningen, the Netherlands, 175-224, ISBN 9070754339, 1994.

Paprotny, D., Kreibich, H., Morales-Nápoles, O., Wagenaar, D., Castellarin, A., Carisi, F., Bertin, X., Merz, B., and Schröter, K.: A probabilistic approach to estimating residential losses from different flood types, Nat. Hazards, 105, 2569-2601, 2021.

Pistrika, A. and Jonkman, S.: Damage to residential buildings due to flooding of New Orleans after hurricane Katrina, Journal of Natural Hazards, 54, 413-434, 2010.

Postacchini, M., Zitti, G., Giordano, E., Clementi, F., Darvini, G., and Lenci, S.: Flood impact on masonry buildings: The effect of flow characteristics and incidence angle, J. Fluid. Struct., 88, 48-70, https://doi.org/10.1016/j.jfluidstructs.2019.04.004, 2019.

Pregnolato, M., Galasso, C., and Parisi, F.: A Compendium of Existing Vulnerability and Fragility Relationships for Flood: Preliminary Results, 12th International Conference on Applications of Statistics and Probability in Civil Engineering, ICASP12 Vancouver, Canada, 12-15 July, 2015.

Reese, S. and Ramsay, D.: RiskScape: Flood fragility methodology, Technical Report, WLG2010-45, available aT: https://www.wgtn.ac.nz/sgees/research-centres/documents/ riskscape-flood-fragility-methodology.pdf (last access: 1 May 2021), 2010.

Roeber, V. and Bricker, J. D.: Destructive tsunami-like wave generated by surf beat over a coral reef during Typhoon Haiyan, Nat. Commun., 6, 1-9, 2015.

Saha, S., Moorthi, S., Pan, H.L., Wu, X., Wang, J., Nadiga, S., Tripp, P., Kistler, R., Woollen, J., Behringer, D., and Liu, H.: The NCEP climate forecast system reanalysis, B. Am. Meteorol. Soc., 91, 1015-1058, 2010.

Sebastian, A., Proft, J., Dietrich, J. C., Du, W., Bedient, P. B., and Dawson, C. N.: Characterizing hurricane storm surge behavior in Galveston Bay using the SWAN + ADCIRC model, Coast. Eng., 88, 171-181, 2014.

Sihombing, F. and Torbol, M.: Analytical fragility curves of a structure subject to tsunami waves using smooth particle hydrodynamics, Smart Struct. Syst., 18, 1145-1167, https://doi.org/10.12989/sss.2016.18.6.1145, 2016.

Skamarock, W. C. and Klemp, J. B.: A time-split nonhydrostatic atmospheric model for weather research and forecasting applications, J. Comput. Phys., 227, 3465-3485, 2008.

Slomp, R., Kolen, B., Bottema, M., and Terpstra, T.: Learning from French Experiences with Storm Xynthia - Damages after A Flood, Learning from large flood events abroad, ISBN 978-9077051-77-1, 2010.

Smith, S. and Banke, E.: Variation of the sea surface drag coefficient with wind speed, Q. J. Roy. Meteor. Soc., 101, 665-673, 1975.

Suppasri, A., Mas, E., Charvet, I., Gunasekera, R., Imai, K., Fukutani, Y., Abe, Y., and Imamura, F.: Building damage characteristics based on surveyed data and fragility curves of the 2011 great east Japan tsunami, Nat. Hazards, 66, 319-341, 2013.

Thapa, S., Shrestha, A., Lamichhane, S., and Adhikari, R.: Catchment-scale flood hazard mapping and flood vulnerability analysis of residential buildings: The case of Khando River in eastern Nepal, J. Hydrol., 30, https://doi.org/10.1016/j.ejrh.2020.100704, 2020.

Tomiczek, T., Kennedy, A., Zhang, Y., Owensby, M., Hope, M., Lin, N., and Flory, A.: Hurricane Damage Classification Methodology and Fragility Functions Derived from Hurricane 
Sandy's Effects in Coastal New Jersey, J. Waterw. Port C., 143, https://doi.org/10.1061/(ASCE)WW.1943-5460.0000409, 2017.

Tranchant, Y., Testut, L., Chupin, C., Ballu, V., and Bonnefond, P.: Near-Coast Tide Model Validation Using GNSS Unmanned Surface Vehicle (USV), a Case Study in the Pertuis Charentais (France), Remote Sensing, 13, 2886, https://doi.org/10.3390/rs13152886, 2021.
Tsubaki, R., Bricker, J. D., Ichii, K., and Kawahara, Y.: Development of fragility curves for railway embankment and ballast scour due to overtopping flood flow, Nat. Hazards Earth Syst. Sci., 16, 2455-2472, https://doi.org/10.5194/nhess16-2455-2016, 2016. 